Journal of Tropical Resources and Sustainable Science

journal homepage: jtrss.org

\title{
A pilot study for sustainable ecotourism at Gunong Stong State Park, Kelantan using Visitor Experience and Resource Protection (VERP) management framework
}

\author{
N.H. Hassin*, A.N.M. Noor, M.A. Nazihah, H.H. Ulfah, A.R.N. Hidayah, M.A. Abas, M.F.A. Karim \\ Faculty of Earth Science, Universiti Malaysia Kelantan, Locked Bag No. 100, 17600 Jeli, Kelantan, Malaysia.
}

Received 20 October 2018

Accepted 13 December 2018

Online 27 May 2019

Keywords:

VERP, Gunong Stong State Park, Ecotourism, Natural Resources, Protected Area.

\*Corresponding author: Mr. Nor Hizami Hassin

Department of Natural Resource and Sustainability, Universiti

Malaysia Kelantan Locked Bag

No. 100, 17600 Jeli, Kelantan,

Malaysia.

Email: hizami.h@umk.edu.my

\begin{abstract}
Ecotourism plays a vital role in tourism industries and has become one of the effective practices towards conservation effort in the natural environment activity. Thus, it is important to know the concept of carrying capacity issues applied to the area pertaining to the visitors' experiences, to ensure the benefits it brings to the socio-cultural, economic, and environmental sustainability of the area. The objective of this study was to identify the relationship of visitors' experience and the protection of the natural resources at Gunung Stong State Park (GSSP) using the management framework of Visitor Experience and Resource Protection (VERP). This approach provided a set of management framework in order to manage the sustainable ecotourism in GSSP without abandoning the good manner of visitor experiences. A total of 35 respondents have participated in this pilot study and our result showed that the tourists' satisfaction towards the GSSP was at moderate level. Therefore, the GSSP was suitable for nature tourism attraction. However, a proper management of the park is required whilst the biodiversity there is still intact. The management of GSSP can be further improved by instilling awareness among visitors in order to sustain the ecotourism activity, and attract more tourists besides improving their experience throughout their visit.
\end{abstract}

(C) 2019 UMK Publisher. All rights reserved.

\section{INTRODUCTION}

The protected area is "an area of land and/or sea especially dedicated to the protection and maintenance of biological diversity which is associated with natural and cultural resources; and managed through legal or other effective means" (Dudley \& Stolton, 2008). It can be summarised that the protected areas are dwindling from any unfavorable human activities in order to save the nature and wildlife from destruction of their resources. Ecotourism is one of the practical ways to support the maintenance of natural areas and contribute to the purposes of protected areas and does not undermine them (Eagles et al., 2002). However, ecotourism activities in protected areas could have both, positive and detrimental effects on the natural resources. Nor Hizami et al., (2014) stated that ecotourism activities in protected areas are usually used for activities such as research, education, legislation, and recreation instead of appreciating of the nature themselves. Some of the positive values are increased support amongst the public or visitors for protected area, addressed the environmental issues in general and generating economic benefits for host communities, organizations and authorities managing natural areas with conservation purposes. Despite the benefits it brought over, the negative impacts should not be forgotten. Some of the examples are the disturbance the visitors might bring to wildlife, userconflicts between the tourists and the local communities.

The Visitor Experience and Resource Protection (VERP) Management Framework is an analytical and indicator framework created by the US National Park Service (USNPS) that suit to be used in both wilderness and non-wilderness surroundings. It focuses on visitor use impacts on the visitor experience and the park resources itself. These impacts are primarily attributable to the visitor behavior, use levels, types of use, timing of use, and location of use (Belnap et al., 1997). It is actually an alteration from the Canadian VAMP (Visitor Activities Management Process) system and builds on the basic framework used in the LAC (Limits of Acceptable Change). It is built based on the concept of carrying capacity and the desire to maintain quality resources and quality visitor experiences in order to help in decisions making for carrying capacity issues (Eagles et al., 2002). In short, the VERP management framework that were developed to address the visitor management challenge is also important in emphasizing the establishment of management objectives, indicators, standards, monitoring and developing appropriate management actions (Walther, 1986). Therefore, the purpose of this study was to identify the relationship between the visitor's experience and protection of the natural resources by using the Visitor Experience and Resource Protection (VERP) management 
framework for managing the sustainable ecotourism at GSSP. The outcome of this study may be useable to ensure that the tourists have an enjoyable and the safety of visitor experience in a manner that will beneficially give positive impacts on the environmental, socio-cultural and economic sustainability of the area.

The findings of the literature study and surveys are used to kick-start the development of possible indicators or thresholds of potential concerns to measure tourism performance and impacts on the environment (Mabunda, 2004). The expected outcome is a generic framework that will evolve in time through adaptive management into a fully integrated tourism management framework. VERP is a process of dealing with the quality of both the resources the visitor experience by the definition of carrying capacity (Nilsen \& Taylor, 1997). VERP process uses indicators, standards and monitoring to identify and manage for desired resource and social conditions (Taylor, 2004). It guides resource analysis through the use of statements of significance and sensitivity, and visitor opportunity analysis is guided by statements defining important elements of the visitor experience (Bernap et al., 1997). This analytical and literative process aims to combine both management planning and operational planning together as one exercise. The emphasis is on strategic decisions pertaining to carrying capacity based on quality resource values and quality visitor experiences. The product is a series of prescriptive management zones defining desired future conditions with indicators and standards (McCool et al., 2007). VERP is particularly useful and comprehensive for establishing a broad direction for the management of human use in protected areas, besides addressing the issue of interpreting natural and cultural resources (Yi et al., 2010). VERP places a threat-specific approach emphasis on identifying factors, indicators, and standards, and on subsequent monitoring. It involves a mechanism for detecting early signals of problems but does not necessarily pinpoint the root causes of the problems. Thus, the successful management of the visitor experience can contribute to maximizing the positive impact of the economic, environmental, and socio-cultural elements of the sustainable tourism will be achieved.

\section{MATERIALS AND METHODS}

\subsection{Study area}

Gunung Stong State Park (GSSP) or Gunung Stong State Forest Park (GSSFP) as it's full title use, is a pristine forest reserve that located in the west of Kelantan state which is about $8 \mathrm{~km}$ from Dabong, $48 \mathrm{~km}$ from Jeli, $103 \mathrm{~km}$ from Tanah Merah and $165 \mathrm{~km}$ from Kota Bharu. The park covers a total area of 61128 hectares(ha) which includes 28134ha of Southern Gunung Stong Reserved
Forest and 11040ha of Northen Gunung Stong Forest Reserve. The area is well-known for the ecotourism activities such as jungle trekking and mountain climbing. It is also famous for its highest waterfall in Southeast Asia with a height of over $200 \mathrm{~m}$, known as the Jelawang Waterfall (Mariana et al., 2005). The Figure 1 below shows the location of GSSP.

\subsection{Data collection}

In this study, a questionnaire has been designed to gather and collect primary information from the visitors' in term of their experiences, perception and park management. Initially, the management personnel of GSSP were contacted to obtain approval on performing the study. Then, a questionnaire was sent via e-mail to the pertinent contact person in order to obtain the information needed. The returned questionnaire was briefly reviewed to check for any missing or mistaken information, and clarity of the questions. The management of GSSP was re-contacted either by e-mail or telephone to arrange for the commencement of study and time taken to finish. The questionnaire was designed in a simple mode, in which respondents only need to tick the selected answer using close ended question and five-points Likert scale from 1 5 level of selection to reduce the time for completion. Faceto-face interview was conducted to obtain the information from the visitors. This study was a pilot assessment to investigate the potential of GSSP for sustainable ecotourism destination using VERP. Thus, a sample size of 35 respondents were taken in this survey. The interview questions focussed on pertinent issues in managing visitors especially zoning plan, visitors' behaviour and conflicts. In addition, respondents were also asked about the conditions of GSSP's resources and the ability of the existing resources to sustain the number of visitors to the park.

\subsection{Data analysis}

The suitability of GSSP as tourism site were assessed based on the World Tourism Organization proposal, proposed by McNeely et al., (1992). This checklist was used for deciding whether GSSP is suitable for tourism through direct observation process. Data were compiled and grouped into four categories namely flagship attractions, complementary and supporting attractions, accessibility and regional infrastructure, and general political as well as social framework (Nilsen \& Taylor, 1997). All the data has been compiled and analysed to give well founded suggestion. Analysis was carried out based on VERP framework to provide valuable insights on park resources and existing visitor use. This analysis will be used as a guideline to help define decision making and management action that may be appropriate for GSSP to mitigate visitor impacts and management constraints. 


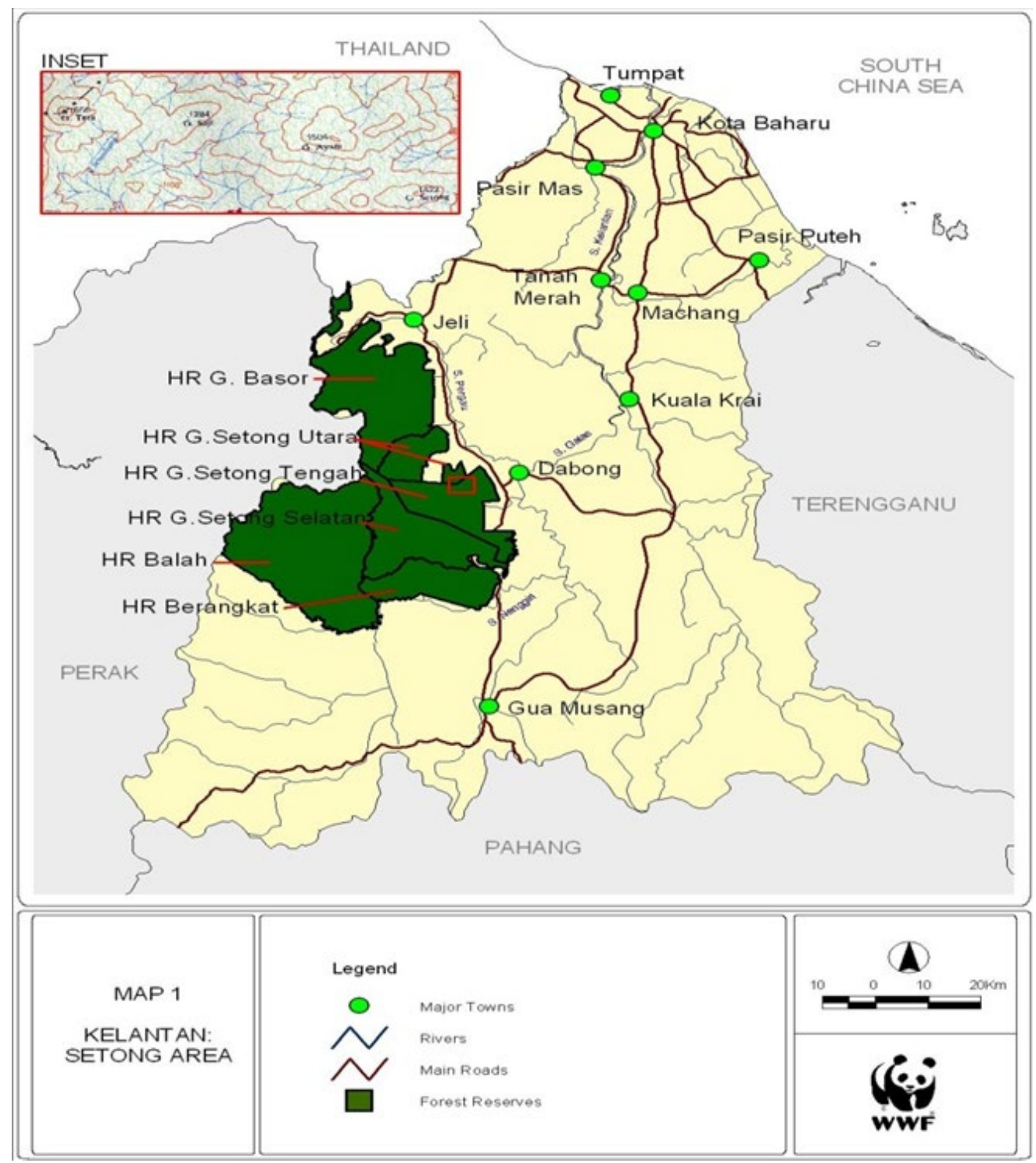

Figure 1: Maps of Gunong Stong State Park, Kelantan (Source: World Wildlife Fund, 2018).

\section{RESULTS AND DISCUSSION}

\subsection{Respondents demographic profile}

A summary of respondents' socioeconomic profile was presented in Table 1. In term of genders, most of the respondents were male $(71.4 \%)$. The result was comparable with other studies (Nor Hizami et al., 2014; Zaiton Samdin et al., 2013; Mohd Rusli et al., 2008), at the nature tourism destinations which is most of the male are likely to visits rather than female. From the perspective of respondent's age, the majority were young (82.8\%), between 20 and 39 years of age. The result also showed that the respondents were dominantly from local visitors with $94.3 \%$. However, two international visitors $(5.9 \%)$ also came to the park at the time of the study was conducted. From the employment standpoint, majority of respondents were self-employed $(45.7 \%)$. The private and government sector are equal with $20.0 \%$ and the least was the student respondents $(14.3 \%)$. The uniqueness, attractions and experiences to be gained by the visitors were the major factors that representation visitors to the
GSSP. Thus, the result shows that $60.0 \%$ of the respondents visited GSSP for the first time while $28.6 \%$ arrived for the second time and only $11.4 \%$ of the respondents have never been to GSSP. This study also found that most of the repeated visitation was among the mountain hikers and the local community to enjoy the beautiful scenery and activity provided at GSSP. Besides, a number of visitors from agencies or institutions had stayed overnight because they were involved with leadership camp or hiking activities organised by their institutions. As for the duration of visitation, $51.4 \%$ of the 35 respondents had visited and stayed overnight at the park while $34.2 \%$ of the respondents had spent their time between 3 to 6 hours to enjoy the recreational activity provided at the park. GSSP offered an amazing waterfall which is the highest waterfall in South East Asia and fascinating surrounding. Thus, about $68.6 \%$ of the respondents stated that they have never visited the similar place such in GSSP while $31.4 \%$ of them stated conversely which visited same place such in Taman Negara Gunung Ledang, Johor. 
Table 1: Respondent's demographical profile.

\begin{tabular}{|c|c|c|}
\hline Variables & Frequency & Percentage (\%) \\
\hline \multicolumn{3}{|l|}{ Gender } \\
\hline Male & 25 & 71.4 \\
\hline Female & 10 & 28.6 \\
\hline \multicolumn{3}{|l|}{ Age range } \\
\hline$<20$ & 2 & 5.7 \\
\hline $20-29$ & 14 & 40.0 \\
\hline $30-39$ & 13 & 37.1 \\
\hline $40-49$ & 3 & 8.6 \\
\hline $50-59$ & 2 & 5.7 \\
\hline$>60$ & 1 & 2.9 \\
\hline \multicolumn{3}{|l|}{ Nationality } \\
\hline Locals & 33 & 94.3 \\
\hline Internationals & 2 & 5.7 \\
\hline \multicolumn{3}{|l|}{$\begin{array}{l}\text { Respondent's } \\
\text { occupation }\end{array}$} \\
\hline Government & 7 & 20.0 \\
\hline Private & 7 & 20.0 \\
\hline Self-employed & 16 & 45.7 \\
\hline Student & 5 & 14.3 \\
\hline \multicolumn{3}{|c|}{$\begin{array}{l}\text { Number of previous } \\
\text { visitation }\end{array}$} \\
\hline$>2$ & 0 & 0.0 \\
\hline 2 & 10 & 28.6 \\
\hline 1 & 21 & 60.0 \\
\hline 0 & 4 & 11.4 \\
\hline \multicolumn{3}{|l|}{$\begin{array}{l}\text { Duration of } \\
\text { visitation }\end{array}$} \\
\hline 1-2 hours & 4 & 11.4 \\
\hline 3-4 hours & 6 & 17.1 \\
\hline 5-6 hours & 6 & 17.1 \\
\hline $7-8$ hours & 1 & 2.9 \\
\hline$>24$ hours & 18 & 51.4 \\
\hline \multicolumn{3}{|c|}{$\begin{array}{l}\text { Visited similar place } \\
\text { to GSSP }\end{array}$} \\
\hline Yes & 11 & 31.4 \\
\hline No & 24 & 68.6 \\
\hline
\end{tabular}

\subsection{GSSP visitation}

According to the information gathered from the staff of the park, most of the visitors came during weekends and school holidays because this site is known to be one of the popular destinations for recreational activity. As for the purpose of visitation, $28.6 \%$ from the 35 respondents have visited GSSP for nature and wildlife observation. GSSP is known for its waterfall and beautiful scenery on top of the mountain that indicated by second largest percentage with $25.7 \%$ of the respondents have visited the park for hiking, $20.0 \%$ for jungle trekking, $14.3 \%$ for leisure of holiday and lower percentage of the respondents visited GSSP for educational and research work with $5.7 \%$ respectively. This can be seen through observation on the visitation characteristics at GSSP where most of the visitors came to enjoy the aesthetic value of the park as shown in Figure 2.

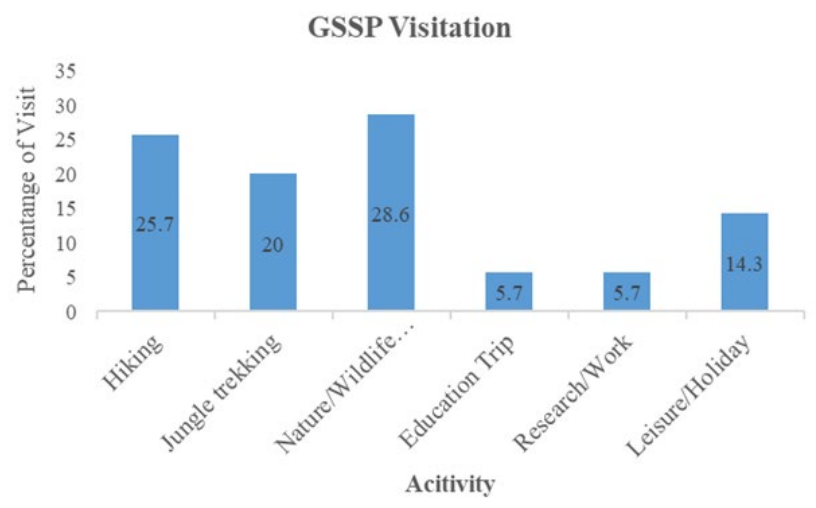

Figure 2: The percentage of the visitation purpose.

\subsection{Visitors experience of management of natural resource}

Overall, most of the respondents (76\%) stated that they have medium level of satisfaction towards GSSP as presented in Figure 3. Meanwhile, only $12 \%$ of the respondents agreed that they have low and high level of satisfaction towards their experience and management of natural resources at GSSP. The dissatisfaction expressed by respondents was due to several aspects of the park, such as the facilities and cleanliness of the park that have not been managed properly by authority of the park.

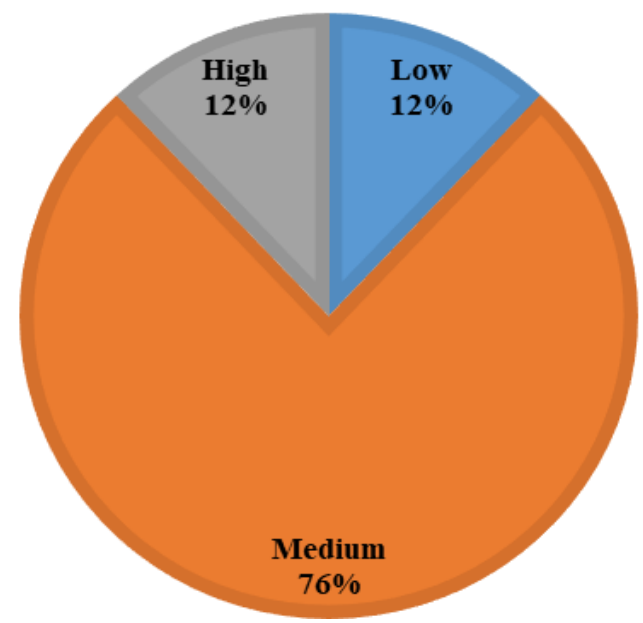

Figure 3: The level of visitor's satisfaction.

\subsection{Visitors satisfaction and experiences}

Visitors satisfaction and experience gained are the prominence elements to determine the level of quality services provided at the recreational destination (Naidoo et al., 2011). In this study (Table 2), the results were measured on five-point Likert scales from "not satisfactory at all" to "very satisfactory". By referring to the mean for the level of satisfaction, the result shows that the accessibility to the GSSP indicated a high level of satisfaction with a mean value of 4.86. The GSSP was easy to find due to strategic signage placement along the main road and was easily accessible by any vehicles. Meanwhile, the lowest mean value with 1.60 was found by the lack of the facilities in term of information center provided at the park. The information center is vital because it represents 
a valuable resource for providing information on the spot and for influencing the visitor's choice of destination (Ispas et al. 2014). Besides, the result also showed that $60.0 \%$ of the respondent were dissatisfied with the public toilet due to improper management.

Table 2: Visitors Satisfaction and Experience.

\begin{tabular}{lllllll}
\hline Items & \multicolumn{8}{c}{ Satisfaction level } \\
\cline { 2 - 6 } & Mean & NS & US & MS & S & VS \\
& $(\%)$ & $(\%)$ & $(\%)$ & $(\%)$ & $(\%)$
\end{tabular}

\begin{tabular}{|c|c|c|c|c|c|c|}
\hline \multicolumn{7}{|l|}{$\begin{array}{l}\text { Experience gained meet } \\
\text { the expectation of } \\
\text { visitation purpose }\end{array}$} \\
\hline - Hiking & 4.49 & 0.0 & 0.0 & 5.7 & 40.0 & 54.3 \\
\hline $\begin{array}{l}\text { - Jungle trekking } \\
\text { - Wildlife/nature }\end{array}$ & 4.31 & 0.0 & 0.0 & 2.9 & 62.9 & 34.3 \\
\hline observation & 4.80 & 0.0 & 0.0 & 0.0 & 20.0 & 80.0 \\
\hline - Water-based activities & 4.26 & 0.0 & 0.0 & 5.7 & 62.9 & 31.4 \\
\hline - Camping/Picnic/Leisure & 4.54 & 0.0 & 0.0 & 0.0 & 45.7 & 54.3 \\
\hline \multicolumn{7}{|l|}{$\begin{array}{l}\text { Satisfaction with the } \\
\text { facilities provided by the } \\
\text { park }\end{array}$} \\
\hline - Public Toilet & 1.71 & 34.3 & 60.0 & 5.7 & 0.0 & 0.0 \\
\hline - Accommodation & 2.54 & 0.0 & 54.3 & 37.1 & 8.6 & 0.0 \\
\hline - Campsite & 4.49 & 0.0 & 0.0 & 0.0 & 51.4 & 48.6 \\
\hline - Tour guide & 4.69 & 0.0 & 0.0 & 2.0 & 26.6 & 71.4 \\
\hline - Information centre & 1.60 & 45.7 & 48.6 & 5.7 & 0.0 & 0.0 \\
\hline - Accessibility/route & 4.86 & 0.0 & 0.0 & 0.0 & 14.3 & 85.7 \\
\hline - Signage and tagging & 2.11 & 14.3 & 42.8 & 34.3 & 8.6 & 0.0 \\
\hline \multicolumn{7}{|l|}{$\begin{array}{l}\text { Visitor's opinion on the } \\
\text { uniqueness of the park }\end{array}$} \\
\hline - Natural features & 4.68 & 0.0 & 0.0 & 2.8 & 28.6 & 68.6 \\
\hline $\begin{array}{l}\text { - Diversity of flora and } \\
\text { fauna }\end{array}$ & 4.77 & 0.0 & 0.0 & 0.0 & 22.9 & 77.1 \\
\hline - Ecotourism activities & 4.17 & 0.0 & 0.0 & 11.4 & 60.0 & 28.6 \\
\hline
\end{tabular}

NS: Not satisfactory at all

US: Unsatisfactory.

MS: Moderately satisfactory.

S: Satisfactory.

VS: Very satisfactory.

A total of $42.8 \%$ of the respondents were unsatisfied with the signage and tagging followed by $54.3 \%$ of them were not satisfied with the accommodation provided at the park. According to Hughes and Morrison (2002), interpretive signs and tagging provides an important tool for enhancing visitor knowledge and understanding during a natural area experience. For examples, tagging on the plants and trees, especially the unique species can it give some educational experience to the visitors. However, majority of the respondents indicated at satisfactory level for the aspect of tour guide and campsite with $71.4 \%$ and $51.4 \%$ respectively. In terms of experience gained that met the expectation of visitation purpose, the survey result stated that $80 \%$ of the respondent were mostly satisfied with the diversity of wildlife and nature observation, followed by hiking and camping at GSSP with 54.3\% respectively. At the same time, 62.9\% of the respondents mentioned that they are satisfactory with the jungle trekking and water-based activities offered by the GSSP. Meanwhile, $68.6 \%$ of the respondents agreed that the natural features which existed at the GSSP was the one of the main reasons that attracted visitors to visit. Furthermore, GSSP has a unique and interesting waterfall which is among the highest in Southeast Asia and is easy to see upon entering the park. As for the diversity of flora and fauna, $77.1 \%$ of the respondents pointed out that they were very satisfied and the ecotourism activities offered at GSSP such as wildlife observation, climbing, jungle trekking, etc. indicated by $60.6 \%$ level of satisfactory.

\subsection{Direct observation and interview analysis}

While carrying out the study in the park, direct observation on the facilities and the resources together with the interview with a staff of GSSP had also been done. Based on the interview session, it was known that the park management emphasized more on the visitor's experience with nature, adventure, leisure and education. The activities provided at the park includes hiking, trekking, nature/wildlife observation, camping, and others which aimed to give the visitor's experience and satisfaction when they entered at the GSSP. According to the park management, the park had received numerous visitors every year. But, since they are having lack of human resource, the park is not fully managed to the extent. Although the park management has been trying their best to monitor the visitor's activity, there were still facing certain problems that could be challenging to overcome due to lack of funding and poor income generation. The park management also faced some challenges in managing the visitors. Some of the visitors were not willing to pay the entrance fee and littered everywhere.

Some visitors of GSSP tend to throw rubbishes anywhere in the park area (Figure 4a) including the river instead of using the dustbins provided by the park management in the park area. The garbage includes plastic bottles, food wrappings and even 'pampers' (i.e. baby diapers). Although this situation was just slightly affected the surrounding of the park (as all the workers always clean up the litter thrown by the visitors), but it gave a negative impression of the park to the other visitors, especially foreigners. This also caused eye sore and uncomfortable feelings from every person who came by and affect the satisfaction level of their experiences. As for the facilities, through direct observation, the facilities were not properly managed. For instance, there were water leakages (Figure $4 \mathrm{~b}$ and Figure 4e) in a few identified areas in the park, which included some chalets and a nearby trail. If the leakage problems are not being solved, the cost of managing the area will increase since the leakage caused a lot of water to be wasted. Besides that, some of the trails were slightly damaged and have the probability of causing danger to the visitors. The kid's water recreation (Figure 4d) area also were not properly managed, as it was dirty. But still, the visitors took bath and have their water-based activities there even though it might affect their experience as shown detail in Figure 4. 


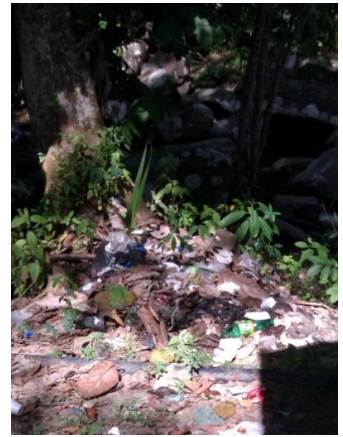

(a)

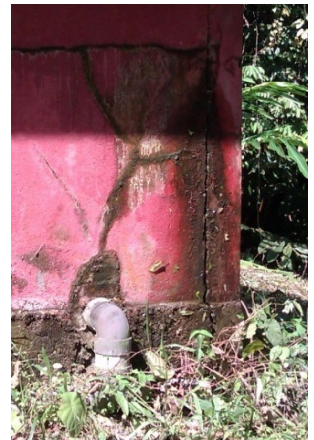

(b)

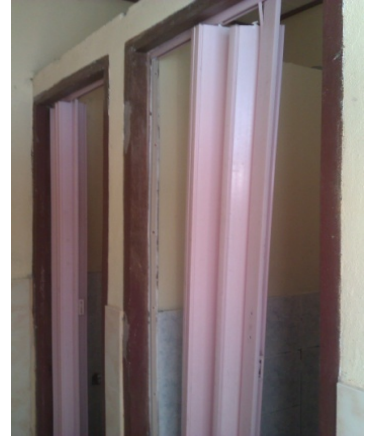

(c)

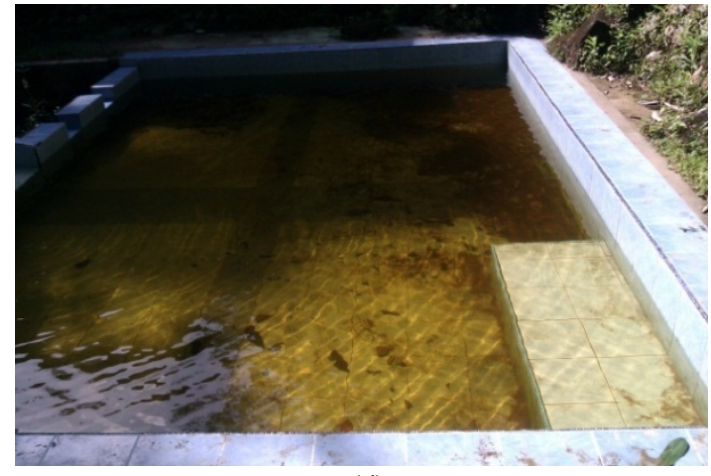

(d)

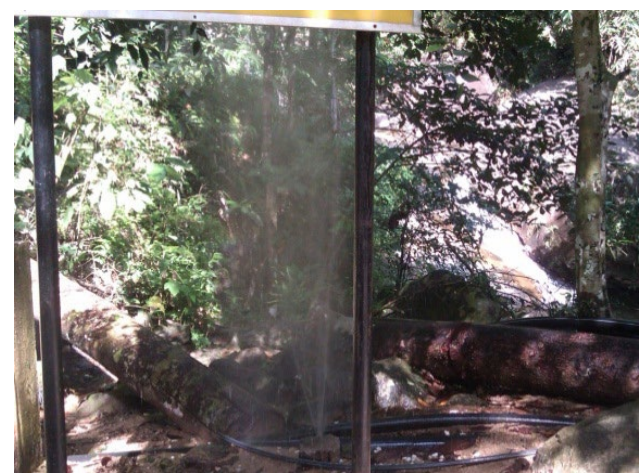

(e)

Figure 4: The facilities condition at Gunong Stong State Park, (a) rubbishes from food and drink containers, (b) water tank leakage, (c) broken door of a toilet, (d) unwell children's water recreation area, and (e) water pipe leakage.

\subsection{WTO / UNDP criteria for tourism site suitability}

The suitability of the GSSP as a nature tourism site was assessed based on the World Tourism Organization (WTO, 1992) proposal. Table 3 shows the checklist that was used for deciding the suitability of the park for tourism through direct observation. Based on the four criteria of suitability, the study found that most of the characteristics in the criteria were fulfilled by the GSSP. Meaning, that the park is suitable to be a nature tourism attraction. Flagship attractions in the park include the uniqueness of species, types of landscape and topography and wide range of observable flora and fauna. GSSP also has many supporting attractions such as the opportunity of adventure and water-based activity. The park also has necessary facilities nearby, such as a local clinic, road access, interesting attractions and landscapes, and more.

\section{CONCLUSION}

The future of managing visitors and issues relating to sustainable ecotourism need not be constrained by the challenges of applying a suitable method to assess and administer the visitor experience as well as the natural resources. From the assessment made on GSSP in this pilot study, the visitor impact, ecology, culture and social issues were being stressed on. This study was done by visiting the park, and making conversation with the managerial team and most importantly, the visitors through a set of questionnaires and interviews. Since its establishment or public opening, GSSP received visitors who came for various purposes. Moreover, the perpetually of number of visitors is still remains as there are promotional efforts made by authorities to sustain the natural resources of the park besides to attract more visitors. From the results, the level of tourists' satisfaction towards the GSSP was moderate indicating that the park is suitable as a nature tourism attraction. However, a proper management of the park is required whilst the biodiversity there is still intact. Instilling awareness among visitors could help improve the management of GSSP, sustain the ecotourism activities, and attract more tourists besides improving their experience throughout their visits.

\section{ACKNOWLEDGEMENT}

The authors would like to acknowledge the Faculty of Earth Science, Universiti Malaysia Kelantan, Kelantan Forestry Department and the authority of Gunong Stong State Park for the providing assistance during the conducting of the research. 
Table 3: Checklist of suitability for Gunung Stong State Park as ecotourism attractions.

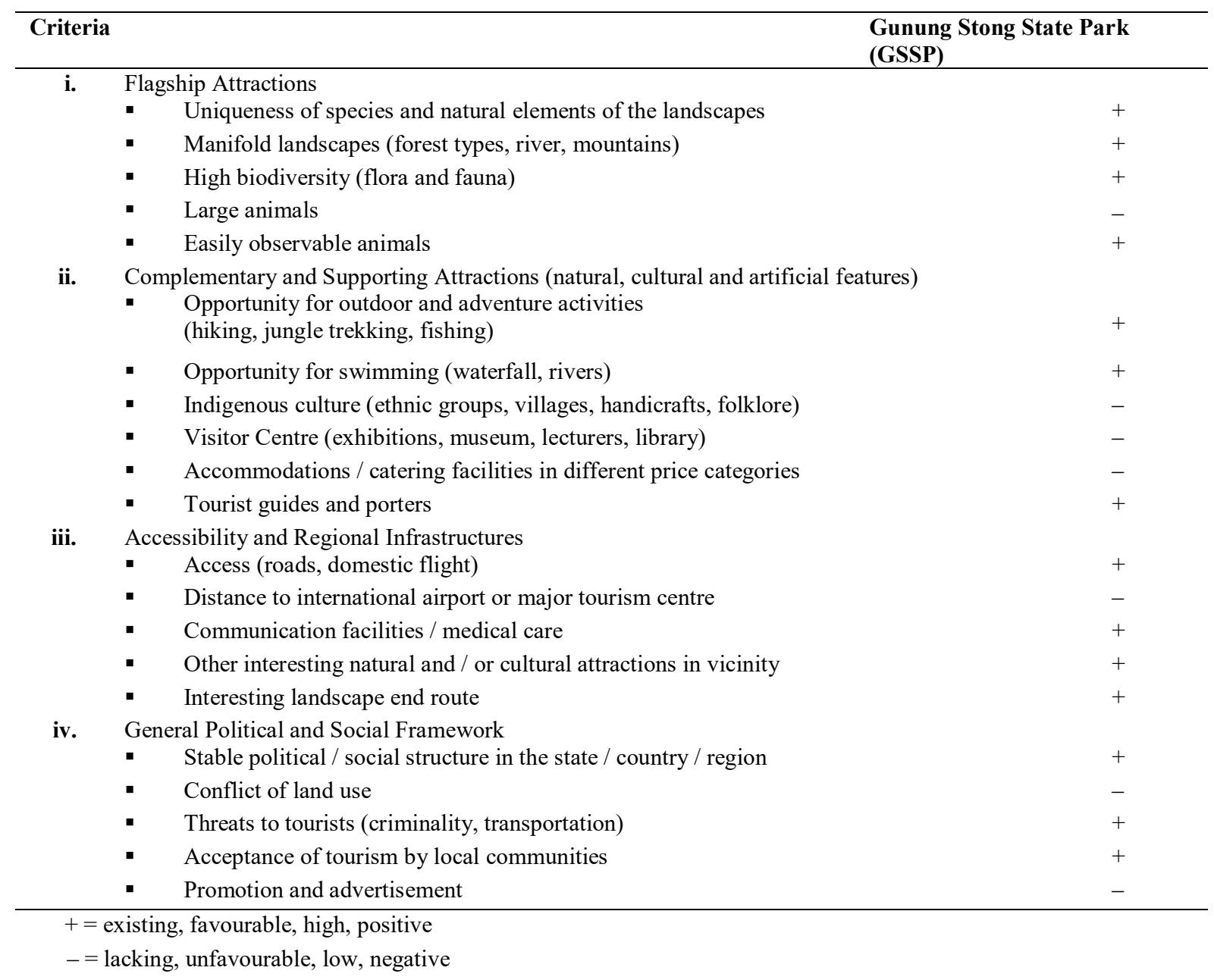

\section{REFERENCES}

Belnap J., Freimund W.A., Hammett J., Harris J., Hof M., Johnson G., Lime D.W., Manning R.E., McCool S.F., and Rees M. (1997). The Visitor Experience and Resource Protection (VERP) Framework: A Handbook for Planners and Managers, U.S. Department of the Interior and National Park Service.

Dudley, N., \& Stolton, S. (2008). Defining protected areas: an international conference in Almeria, Spain. IUCN, Gland.

Eagles, P. F., McCool, S. F., Haynes, C. D., \& Phillips, A. (2002) Sustainable tourism in protected areas: Guidelines for planning and management (Vol. 8). Gland: IUCN.

Hughes, M., \& Morrison-Saunders, A. (2002). Impact of trail-side interpretive signs on visitor knowledge. Journal of Ecotourism, 1(23), 122-132.

Ispas, A., Rada, D., \& Sava, A. (2014). The Role of Information Centres in Promoting Tourist Destinations Case Study: Tourist Information Centre Brasov. Bulletin of the Transilvania University of Brasov. Economic Sciences. Series V, 7(1), 123.

Mabunda, M. D. (2004). An Integrated Tourism Management Framework for the Kruger National Park: South Africa, 2003. Department of Tourism Management. Pretoria, University of Pretoria.

Mariana A., Zuraidawati Z., Ho T.M., Mohd Kulaimi B., Saleh I., Shukor M.N., \& Shahrul Auar M.S. (2005). A survey of ectoparasites in Gunung Stong Forest Reserve, Kelantan, Malaysia, Southeast Asian J Trop Med Public Health. 36(5): 1125-1131.

McCool, S. F., Clark, R. N., \& Stankey, G. H. (2007). An Assessment of Frameworks Useful for Public Land Recreation Planning (Gen.
Tech Rep. PNW_GTR 705). Portland, OR: USDA ForestService, Pacific Northwest Research Station.

McNeely, J. A., Thorsell, J. W., \& Ceballos-Lascurain, H. (1992). Guidelines, development of national parks and protected areas for tourism (No. 13). World Tourism Organization Pubns.

Mohd Rusli, Y., Alias, R., \& Khairil, W. A. (2008). Economic valuation of marine parks ecotourism Malaysia. Serdang, Selangor: Universiti Putra Malaysia Press.

Naidoo, P., Ramseook-Munhurrun, P., \& Seegoolam, P. (2011). An assessment of visitor satisfaction with nature-based tourism attractions.

Nilsen P., \& Tayler G. A. (1997). Comparative Analysis of Protected Area Planning and Management Frameworks.

Nor Hizami. H., Mohd Rusli Y. \& Alias R. (2014). Valuing Natural Resources of Ecotourism Destination in Taman Negara Sungai Relau, Pahang. Malaysia. Australian Journal of Basic and Applied Sciences. 8 (3). 416-425. ISSN:1991-8178.

Taylor D.W., (2004). Managing the Visitor Experience within Europe's Protected Areas. University of Pretoria etd - Mabunda, M. D (2004).

Walther, P. (1986). The meaning of zoning in the management of natural resource lands. Journal of Environmental Management, 22, 331343.

Yi C.H, Cheng P.W., \& Yu F.L. (2010). Integrating experience-based zoning into current management system in Yu Shan National Park.

Zaiton, S., Yuhanis, A. Z., Alias, R. \& Mohd Rusli, Y. (2013). Sustainability of ecotourism resources at Taman Negara National Park: Contingent Valuation Method. International Journal of Business and Society, 14 (2), 235-244 